\title{
A modern series of subdiaphragmatic craniopharyngiomas
}

\author{
Ali O. Jamshidi, MD, ${ }^{1}$ André Beer-Furlan, MD, ${ }^{1}$ Daniel M. Prevedello, MD, ${ }^{1,2}$ Ronald Sahyouni, PhD, ${ }^{3}$ \\ Mohamed A. Elzoghby, MD, ${ }^{4,5}$ Mina G. Safain, MD, ${ }^{6}$ Ricardo L. Carrau, MD, ${ }^{1,2}$ John A. Jane Jr., MD, ${ }^{4}$ \\ and Edward R. Laws, MD 6
}

Departments of ${ }^{1}$ Neurological Surgery and ${ }^{2}$ Otolaryngology-Head and Neck Surgery, Wexner Medical Center, The Ohio State University College of Medicine, Columbus, Ohio; ' ${ }^{3}$ Department of Biomedical Engineering, University of California, Irvine, California; ${ }^{4}$ Department of Neurosurgery, University of Virginia Health System, Charlottesville, Virginia; ${ }^{5}$ Neurosurgery Department, Ain Shams University, Cairo, Egypt; and ${ }^{6}$ Department of Neurosurgery, Brigham and Women's Hospital, Harvard Medical School, Boston, Massachusetts

\begin{abstract}
OBJECTIVE The endoscopic endonasal approach has been proposed as a primary surgical strategy for select craniopharyngiomas. However, those tumors that arise from the sella have not been classified with the other craniopharyngioma subtypes in terms of surgical nuances, intraoperative findings, and postoperative outcomes. The authors describe their experience with a select subtype of craniopharyngioma arising within the sella subjacent to the diaphragma sellae and refer to these tumors as type 0 .
\end{abstract}

METHODS After obtaining IRB approval, three institutions retrospectively reviewed their data collected from 2005 to 2017. Patients eligible for inclusion in the study were those who had tumors that originated from the sella inferior to the diaphragma sellae. Demographic, clinical, radiological, surgical, and follow-up data were examined and analyzed.

RESULTS Twenty-eight patients (average age 19.3 years, range 3-60 years) were included in this study. Sixteen patients (57\%) were younger than 18 years of age. All patients had characteristic imaging features of an expanded sella. Seventy-five percent of the patients presented with some form of visual field deficit ( $89 \%$ had radiographic optic apparatus compression) and 39\% with hypopituitarism. The average maximal tumor diameter in the axial, coronal, or sagittal plane was $3.1 \mathrm{~cm}$. Gross-total resection was achieved in $82 \%$ of the patients. Twenty-one percent of patients experienced an iatrogenic complication, and there were only two cases (7\%) of postoperative cerebrospinal fluid (CSF) leakage. Only two patients (7\%) required the use of a nasoseptal flap as part of their original reconstruction. Pathology was uniformly the adamantinomatous subtype. Postoperative objective visual outcomes were improved in $71 \%$ of the patients with visual symptoms or visual field deficits on presentation and stable in $24 \%$. Mean follow-up was 45.1 months (range 3-120 months) with an 18\% recurrence rate at a mean of 44.4 months (range 10-84 months). One patient was lost to follow-up. Thirty-six percent of patients received postoperative radiation to treat recurrence or residual tumor. Endocrine data are also presented.

CONCLUSIONS Craniopharyngiomas that originate within the sella below the diaphragma sellae are a select subtype characterized by 1) an enlarged sella, 2) an intact diaphragma sellae at surgery, and 3) an adamantinomatous pathology. These tumors can be treated transnasally without the absolute need for neurovascular flap reconstruction, as there is a low risk of CSF leakage.

https://thejns.org/doi/abs/10.3171/2018.4.JNS172330

KEYWORDS cerebrospinal fluid leak; craniopharyngioma classification; endoscopic; endonasal approach; pedicled nasoseptal flap; pituitary surgery

RANIOPHARYNGIOMAS arise from trapped ectopic or residual squamous cell nests after the hypophyseal-pharyngeal duct involutes during development. Therefore, these tumors can be theoretically found along a tract extending from the oropharynx to the infundibulum, the tuber cinereum, and the floor of the third ventricle. ${ }^{1,6,14}$ Historically, craniopharyngiomas have been classified according to their relationship with the sella, diaphragma sellae, optic apparatus, and third ventricle..$^{7,12,19}$

Craniopharyngiomas have been referred to as "prechi-

ABBREVIATIONS DI = diabetes insipidus; $E E A=$ endoscopic endonasal approach.

SUBMITTED September 16, 2017. ACCEPTED April 26, 2018.

INCLUDE WHEN CITING Published online October 26, 2018; DOI: 10.3171/2018.4.JNS172330. 
asmatic" or "retrochiasmatic." Prechiasmatic tumors can displace the optic chiasm and the anterior cerebral artery complex superiorly and posteriorly. Retrochiasmatic masses grow toward the third ventricle and displace the chiasm anteriorly against the tuberculum sellae. Other than describing their location, these classifications imply corresponding surgical approaches. For example, prechiasmatic tumors are traditionally removed via a pterional approach or a variation of the frontotemporal orbital craniotomy. For craniopharyngiomas that expand the sella and are primarily located in the subdiaphragmatic space, Laws has asserted that the transsphenoidal route is the most appropriate. ${ }^{12}$

Because craniopharyngiomas are ventral midline tumors of the skull base, they can typically be accessed via a midline endoscopic endonasal approach (EEA). In order to help describe the surgical strategy in the context of an EEA, Kassam et al. published a classification system describing craniopharyngiomas according to their location relative to the infundibulum. ${ }^{9}$ This proposed scheme organized these neoplasms into four categories: preinfundibular (type I), transinfundibular (type II), retroinfundibular (type III), and isolated third ventricular or optic recess tumors (type IV). ${ }^{9}$ Kassam and colleagues proposed specific nuances related to the resection of each subtype and discussed the advantages of the EEA for craniopharyngiomas so long as the tumor is not restricted to the third ventricle. ${ }^{9}$ Their article did not describe a subtype of craniopharyngioma that arises within the sella inferior to the diaphragma sellae. We seek to characterize this subtype of craniopharyngioma by adding a type 0 to their classification system.

\section{Methods}

After obtaining IRB approval, we performed a retrospective chart review of data collected from 2005 to 2017 at three separate tertiary care neurosurgery inpatient sites to identify patients with type 0 craniopharyngiomas. Demographic, clinical, radiological, surgical, and follow-up data were examined and analyzed. Statistical analysis was performed using PASW Statistics 18.0 software (SPSS Inc.) and Microsoft Excel (Microsoft Corp.). A p value $<0.05$ was considered statistically significant. A two-sample t-test assuming unequal variances was performed to compare maximal tumor dimensions between patients experiencing complications and those who did not have a complication. A similar analysis was conducted for patients with residual tumor compared to those with gross-total resection, as well as for patients who developed panhypopituitarism following tumor resection compared to those who did not.

\section{Results}

A total of 124 craniopharyngioma patients were screened, and 28 type $0(22.6 \%)$ craniopharyngioma patients (18 males, 10 females) from the three institutions were included in this retrospective cross-sectional study (Table 1). The average patient age was 19.3 years (16.4

TABLE 1. Overview of clinical and outcome parameters of all patients

\begin{tabular}{|c|c|c|c|c|c|}
\hline & Male & Female & Total & $p$ Value & Notes \\
\hline No. of patients & 18 & 10 & 28 & & \\
\hline Avg age in yrs & 16.4 & 24.3 & 19.3 & 0.14 & \\
\hline Visual field Sx/field cut, no. (\%)* & $13(72)$ & $8(80)$ & $21(75)$ & & \\
\hline Panhypopituitary, no. (\%) ${ }^{*}$ & $7(39)$ & $4(40)$ & $11(39)$ & & \\
\hline Optic apparatus compression, no. $(\%)^{*}$ & $16(89)$ & $9(90)$ & $25(89)$ & & \\
\hline Hydrocephalus, no. $(\%)^{*}$ & $0(0)$ & $1(10)$ & $1(4)$ & & \\
\hline Avg max tumor dimension in $\mathrm{cm}^{*}$ & 3.3 & 2.7 & 3.1 & 0.22 & \\
\hline Surgical complication, no. (\%) & $4(22)$ & $2(20)$ & $6(21)$ & & $\begin{array}{l}4 \text { DI, } 2 \text { CSF leaks, } 1 \text { fat graft site infection, } \\
1 \text { transient visual deterioration } \dagger\end{array}$ \\
\hline \multicolumn{6}{|l|}{ Visual outcome, no. (\%) } \\
\hline Improved & $9(50)$ & $6(60)$ & $15(54)$ & & \\
\hline Stable & $4(22)$ & $1(10)$ & $5(18)$ & & \\
\hline Vision normal preop & $5(28)$ & $2(20)$ & $7(25)$ & & \\
\hline No FU & $0(0)$ & $1(10)$ & $1(4)$ & & \\
\hline Recurrence, no. (\%) & $3(17)$ & $2(20)$ & $5(18)$ & & 1 residual in female group \& 4 in male group \\
\hline Avg time to recurrence, mos (range) & $55(32-84)$ & $29(10-48)$ & $44.4(10-84)$ & 0.37 & \\
\hline Postop radiation, no. (\%) & $7(39)$ & $3(30)$ & $10(36)$ & & \\
\hline \multicolumn{6}{|l|}{ Postop radiation type, no. (\%) } \\
\hline Fractionated & $6(86)$ & $2(67)$ & $8(80)$ & & \\
\hline Gamma Knife & $1(14)$ & $1(33)$ & $2(20)$ & & \\
\hline Mean FU in mos (range) & $47.5(11-120)$ & $40.9(3-77)$ & $45.1(3-120)$ & 0.55 & \\
\hline
\end{tabular}

Avg = average; $\mathrm{FU}=$ follow-up; Sx = symptoms

* Indicates finding on presentation.

† Eight complications in 6 patients; 2 patients had 2 complications. 


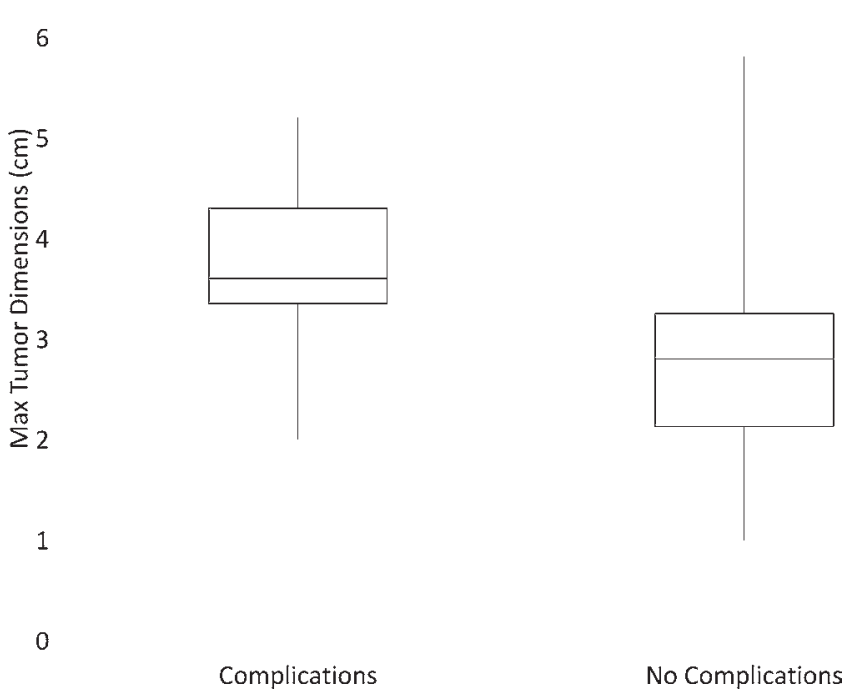

FIG. 1. Box-and-whisker plot of maximal tumor dimensions between patients with complications and those with no complications.

years for males, 24.3 years for females; $p>0.05$ ), and the age range was $3-60$ years. Overall, $75 \%$ of the patients presented with some form of visual field deficit, and $89 \%$ had optic apparatus compression on preoperative imaging. The mean maximal tumor dimension was $3.3 \mathrm{~cm}$ in males, 2.7 $\mathrm{cm}$ in females, and $3.1 \mathrm{~cm}$ overall. Preoperative MRI revealed an expanded sella and the absence of a discernable pituitary gland in all patients. Of note, one female patient presented with hydrocephalus (4\% of the total cohort). All patients had the adamantinomatous craniopharyngioma subtype based on pathological review. At surgery, all patients were found to have an intact diaphragma sellae.

Twenty-six patients underwent EEA and 2 underwent endoscope-assisted microscopic approaches for resection or fenestration of the craniopharyngiomas. Gross-total resection was achieved in $82 \%$ of the patients. In 3 patients with primarily cystic tumors and suprasellar extension, the goal of surgery was fenestration of the cyst into the sphenoid sinus. Silastic stents were placed in 2 of these 3 patients.

Of the 28 patients, 21 (75\%) had visual symptoms or visual field deficits on presentation. Of these 21 patients with visual symptoms, 15 (71\%) had improvement, 5 (24\%) remained stable postoperatively, and 1 (5\%) was lost to follow-up. The 7 patients who had not initially presented with visual symptoms all had normal or stable vision postoperatively (Table 1).

Patients were followed up for an average of 45.1 months (range 3-120 months), during which time tumor recurrence was identified in $18 \%$ of patients. Average time to recurrence was 44.4 months (range 10-84 months). Thirty-six percent of patients with either residual or recurrent tumor received postoperative radiation therapy; $80 \%$ of these patients received fractionated radiotherapy and $20 \%$ underwent radiosurgery (Table 1).

Two patients $(7 \%)$ experienced intraoperative CSF leakage that required nasoseptal flap reconstruction. As
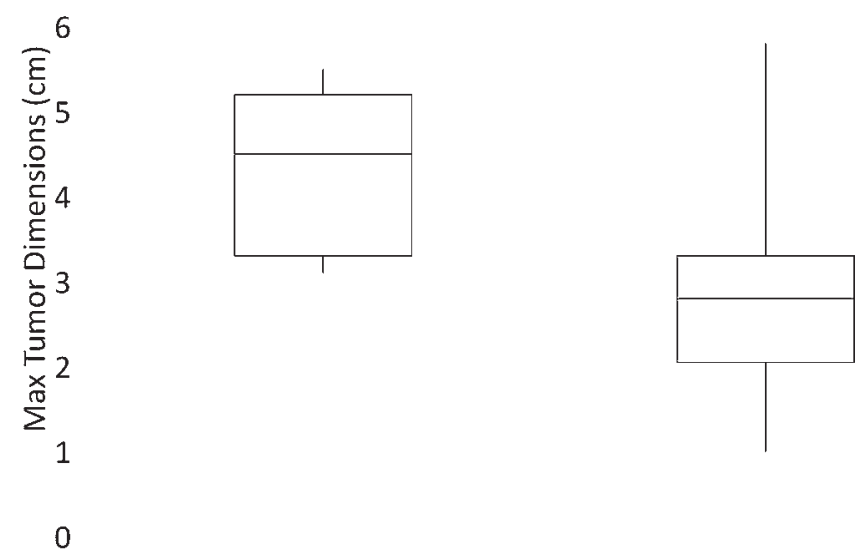

Residual

No Residual

FIG. 2. Box-and-whisker plot of maximal tumor dimensions between patients with residual tumor and those with no residual tumor.

mentioned earlier, the diaphragma sellae was identified in each case and was found to be uniformly intact; however, it was opened in 2 cases during the dissection. Because tumor was adherent to the arachnoid, the diaphragma was inadvertently, but expectedly, opened. Once it was opened, the third ventricle floor was found to be intact and without tumor invasion.

A total of 6 patients $(21 \%)$ experienced complications following surgical intervention (Table 1). There was no statistically significant difference in maximal tumor dimensions between patients who experienced complications and those who did not (Fig. 1). With respect to patients who had residual tumor (18\%) compared to those with gross-total resection, the maximal preoperative tumor dimension was significantly higher in the patients with residual tumor ( $\mathrm{p}<0.05$; Fig. 2).

We collected pre- and postoperative endocrine data (Table 2) for 27 patients; 1 patient was lost to follow-up. With respect to preoperative endocrine function, $15 \%$ (4/27) of patients exhibited panhypopituitarism with diabetes insipidus (DI), 70\% (19/27) exhibited hypopituitarism without DI, $11 \%$ (3/27) exhibited hypopituitarism

TABLE 2. Overview of pre- and postoperative endocrine function

\begin{tabular}{cc}
\hline Endocrine Function & No. (\%) \\
\hline Preop & $4(15)$ \\
\hline Panhypopituitarism w/ DI & $19(70)$ \\
\hline Hypopituitarism w/o DI & $3(11)$ \\
\hline Hypopituitarism & $1(4)$ \\
\hline Normal & \\
\hline Postop & $16(59)$ \\
\hline Stable & $4(15)$ \\
\hline Worsened transiently & $7(26)$ \\
\hline Worsened permanently &
\end{tabular}

* Endocrine data were only collected for 27 patients. 

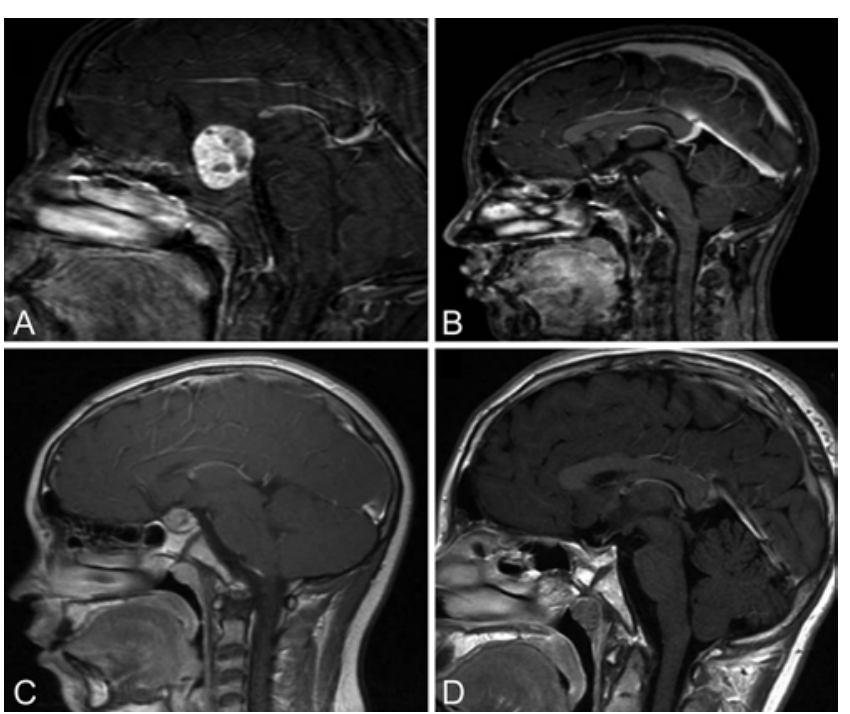

FIG. 3. Case 1. A: Preoperative sagittal contrast-enhanced MR image showing a sellar/suprasellar mass. B: Postoperative MR image showing possible intrasellar residual tumor. C: Tumor recurrence. D: Image obtained post-EEA for resection of recurrent tumor confined to the sella.

with some pituitary function, and 4\% (1/27) had normal pituitary function. With respect to postoperative endocrine function, $59 \%(16 / 27)$ of patients were stable, $15 \%$ (4/27) worsened transiently, and 26\% (7/27) worsened permanently.

Of the patients who initially presented with panhypopituitarism with DI, 75\% (3/4) were stable postoperatively and 25\% (1/4) worsened permanently due to hypothalamic obesity. Of the patients who presented with hypopituitarism without DI, 58\% (11/19) were stable postoperatively, $21 \%$ (4/19) worsened transiently, and 21\% (4/19) worsened permanently. Of the patients who presented with hypopituitarism with some pituitary function, $67 \%(2 / 3)$ were stable postoperatively and 33\% (1/3) worsened permanently. Of the patients who had normal endocrine function preoperatively, $100 \%$ (1/1) worsened permanently after surgery. There was no statistically significant difference in tumor dimension between the 2 patients who developed panhypopituitarism following tumor resection and those who did not.

\section{Illustrative Cases \\ Case 1}

A 15-year-old male presented with a recurrence of his craniopharyngioma, which had been initially diagnosed 4 years earlier. Initially, he had been treated with two craniotomies, followed by adjuvant stereotactic radiation. On routine follow-up imaging, he was found to have a recurrence of his tumor confined entirely to the enlarged sella (Fig. 3). He was on full hormone replacement due to panhypopituitarism. He underwent an EEA, and gross-total resection was achieved with no recurrence at the 4-year follow-up.

\section{Case 2}

A 16-year-old female presented with a history of head-
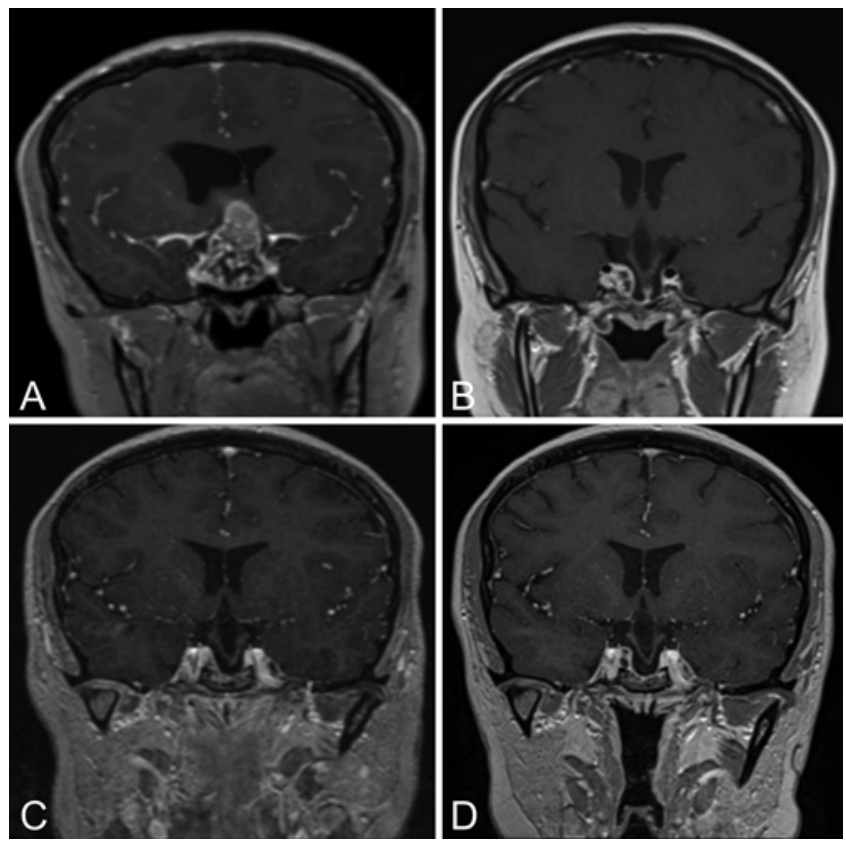

FIG. 4. Case 2. A: Preoperative postcontrast coronal MR image showing tumor expanding the sella and extending into the sphenoid sinus. B: Postoperative enhancing coronal MR image revealing a recurrence in the right parasellar compartment. C: Image obtained after a second EEA for resection of recurrent disease, showing no evidence of residual tumor. D: Coronal MR image obtained about 7 months after the second EEA, showing an asymptomatic recurrence.

ache, nausea, vomiting, and a visual field cut. She also had panhypopituitarism on presentation. Imaging revealed a solid and cystic tumor arising from the enlarged sella, expanding into the sphenoid sinus and extending into the suprasellar compartment. After her first EEA, her vision improved. Because of a recurrence in the right lateral sellar compartment 3 years later, she underwent a second EEA (Fig. 4). Fractionated radiation treatment was applied to a recurrence of the residual tumor on the right side of the sella/cavernous sinus. She was asymptomatic 5 years after the original surgery.

\section{Case 3}

A 10-year-old male presented with developmental impairment and visual deficit. On endocrine evaluation, he was diagnosed with hypopituitarism without DI. He underwent an uncomplicated transsphenoidal approach (Fig. 5). Postoperatively, he developed DI and his vision normalized. The patient has had more than 10 years of followup without evidence of radiographic recurrence (Fig. 6).

\section{Discussion}

Intrasellar craniopharyngioma is thought to account for $7 \%-17 \%$ of all craniopharyngiomas, which is slightly lower than the $22.6 \%$ we report here. ${ }^{17}$ According to several authors, these tumors can displace the diaphragma sellae superiorly, indicating that the tumor can be subdiaphragmatic, confined between the sella and suprasellar compartments. ${ }^{5,13,17,18}$ These tumors can be contained subjacent to a competent diaphragma sellae. Other craniopharyngiomas 

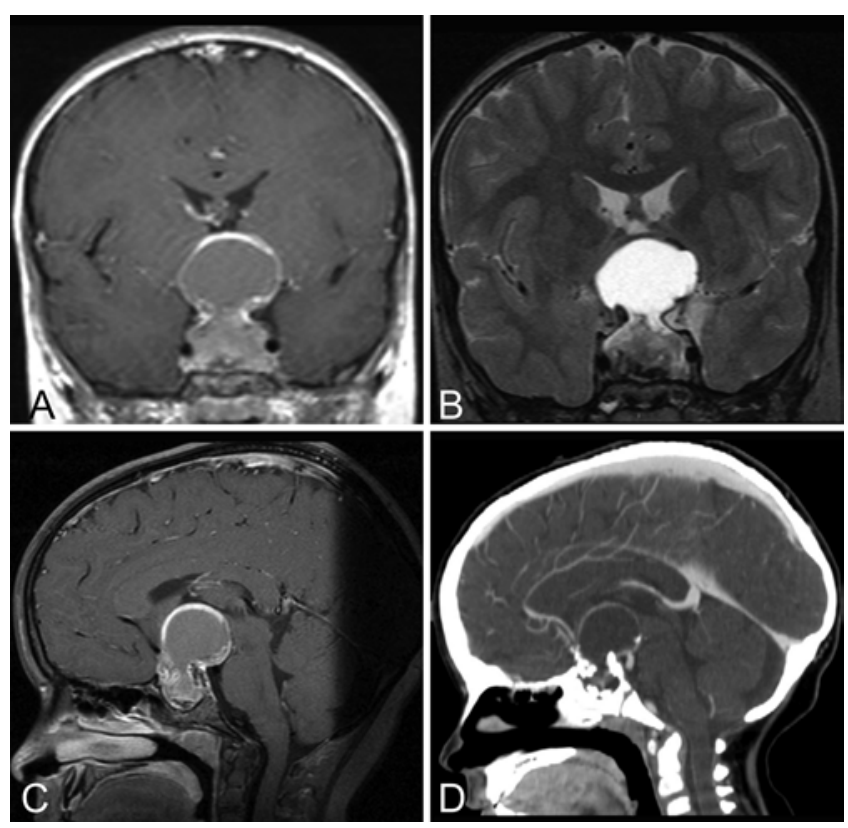

FIG. 5. Case 3. A: Postcontrast coronal T1-weighted MR image revealing a sellar mass with a significant suprasellar cyst, causing compression of the optic apparatus as well as the third ventricle. B: Coronal T2weighted MR image recapitulating these findings and emphasizing the cystic component. C: Sagittal MR image revealing tumor invasion into the sphenoid sinus inferiorly. D: Sagittal CT angiogram does not reveal compression of the anterior cerebral artery complex.

can grow beyond the aperture of the diaphragma sellae and create a radiographic "snowman" appearance similar to giant adenomas that expand toward the third ventricle. These tumors typically remain in a prefixed position relative to the chiasm and can have a thin layer of arachnoid covering the superior pole of the tumor. Despite their potentially large size, these tumors do not necessarily invade the subarachnoid space. Regardless of their relationship to the diaphragma sellae and extent of intracranial extension, we refer to these tumors as type 0 because of their intrasellar and extraarachnoidal origin. ${ }^{4}$

Previous classification systems for craniopharyngio- mas have defined these tumors as confined to the subarachnoid compartment and relative to the infundibulum. ${ }^{9}$ Despite traditional views that these tumors are exclusively found in the subarachnoid space, the pathogenesis of craniopharyngiomas suggests that these tumors can be found as derivatives from oropharyngeal ectoderm along the entire craniopharyngeal tract. ${ }^{11}$ Nevertheless, prior reports, such as those by Yaşargil et al. ${ }^{19}$ and Baldauf et al., ${ }^{3}$ have described subdiaphragmatic craniopharyngiomas.

Because every case presented in the current paper was diagnosed as an adamantinomatous subtype, the likely pathogenesis of the tumors involves neoplastic transformation of ectopic remnants that were confined to the sella. Therefore, these tumors should be considered as extraarachnoidal when radiographic evidence, such as an enlarged sella and an "absent" pituitary gland, suggests a significant sellar component. Typically, it is more difficult to identify the pituitary gland with intrasellar craniopharyngiomas given the fact that the tumor enhances similarly to the gland. Although molecular characteristics confirming molecular deletions were not explicitly assessed in our study, future studies focused on characterizing molecular changes in pathology specimens are warranted.

With regard to clinical and radiological follow-up, all patients had initial MRI immediately postoperatively within 24 hours of surgery. Follow-up MRI was done 3 months after surgery, and patients with residual tumor were followed in 3-month intervals and/or referred for further treatment (surgery or radiation). All patients were followed up annually from the time of surgery with endocrine labs and MRI. In patients without residual tumor or evidence of a recurrence, the MRI follow-up would be done at 6 months and then annually if no further evidence of tumor recurrence was present. Patients also had both inpatient and outpatient endocrine follow-up.

We advocate the use of EEA for resection of this newly described subtype whether for gross-total resection or fenestration. Because type 0 tumors should not involve the subarachnoid space, the surgeon would not expect to visualize the optic apparatus or the superior hypophyseal arteries during surgery. These are critical structures that we aim to identify during expanded transsphenoidal ap-
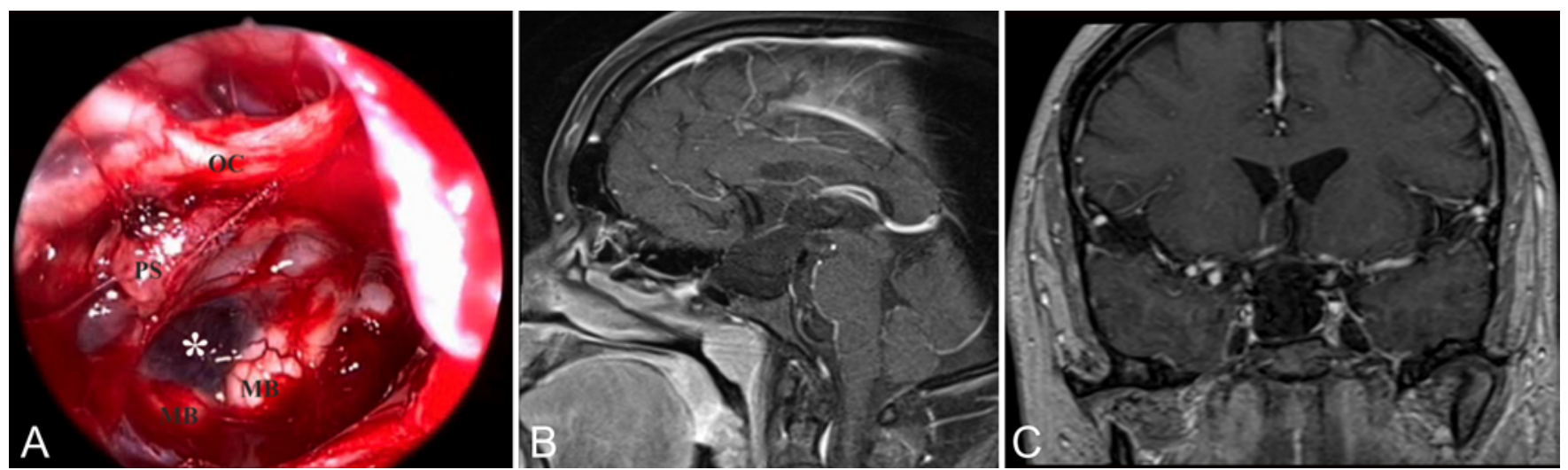

FIG. 6. Case 3. Intraoperative image (A) showing the mammillary body (MB), pituitary stalk (PS), and optic chiasm (OC). Asterisk indicates an intact third ventricle floor. Postoperative sagittal (B) and coronal (C) postcontrast MR images show gross-total resection. Figure is available in color online only. 
proaches in order to maintain a patient's visual function. ${ }^{9}$ Understanding the origin of the tumor as subdiaphragmatic can help surgeons anticipate whether a pedicled nasoseptal flap should be raised prior to opening the sella or whether a rescue flap should be planned instead to reduce morbidity. ${ }^{14,15}$ Furthermore, because there is some suggestion that the nasoseptal flap could be inadequate in size in patients younger than 10 years of age, patients with this tumor subtype can proceed with EEA without the absolute need for intranasal pedicle flap reconstruction. ${ }^{2,16} \mathrm{We}$ found that the patients were appropriately managed with rescue flaps because most often there were no high-flow, iatrogenic CSF leaks encountered during surgery.

\section{Conclusions}

The cases we have described suggest a subdiaphragmatic origin to a subset of craniopharyngiomas that do not necessarily invade the suprasellar subarachnoid space. We believe these tumors, which have been referred to as type 0 craniopharyngiomas, should be treated in a manner similar to pituitary adenomas or Rathke cleft cysts. An endoscopic endonasal transsellar approach is sufficient for resection of this subtype, which can usually be managed without a vascular nasoseptal flap.

\section{References}

1. Adamson TE, Wiestler OD, Kleihues P, Yaşargil MG: Correlation of clinical and pathological features in surgically treated craniopharyngiomas. J Neurosurg 73:12-17, 1990

2. Aydin S, Cavallo LM, Messina A, Dal Fabbro M, Cappabianca $\mathrm{P}$, Barlas $\mathrm{O}$, et al: The endoscopic endonasal trans-sphenoidal approach to the sellar and suprasellar area. Anatomic study. J Neurosurg Sci 51:129-138, 2007

3. Baldauf J, Hosemann W, Schroeder HW: Endoscopic endonasal approach for craniopharyngiomas. Neurosurg Clin $\mathbf{N}$ Am 26:363-375, 2015

4. Beer-Furlan A, Jamshidi AO, Carrau RL, Prevedello DM: Surgical strategy for craniopharyngiomas and the tumorinfundibulum relationship. Neurosurg Focus 43(1):E8, 2017 (Letter)

5. Fahlbusch R, Honegger J, Paulus W, Huk W, Buchfelder M: Surgical treatment of craniopharyngiomas: experience with 168 patients. J Neurosurg 90:237-250, 1999

6. Falavigna A, Kraemer JL: Infrasellar craniopharyngioma: case report. Arq Neuropsiquiatr 59 (2-B):424-430, 2001

7. Hardy J: Transsphenoidal hypophysectomy. J Neurosurg 34:582-594, 1971

8. Hoffman HJ: Surgical management of craniopharyngioma. Pediatr Neurosurg 21 (Suppl 1):44-49, 1994

9. Kassam AB, Gardner PA, Snyderman CH, Carrau RL, Mintz AH, Prevedello DM: Expanded endonasal approach, a fully endoscopic transnasal approach for the resection of midline suprasellar craniopharyngiomas: a new classification based on the infundibulum. J Neurosurg 108:715-728, 2008
10. Komotar RJ, Starke RM, Raper DM, Anand VK, Schwartz TH: Endoscopic endonasal compared with microscopic transsphenoidal and open transcranial resection of craniopharyngiomas. World Neurosurg 77:329-341, 2012

11. Larkin SJ, Ansorge O: Pathology and pathogenesis of craniopharyngiomas. Pituitary 16:9-17, 2013

12. Laws ER Jr: Transsphenoidal microsurgery in the management of craniopharyngioma. J Neurosurg 52:661-666, 1980

13. Maira G, Anile C, Rossi GF, Colosimo C: Surgical treatment of craniopharyngiomas: an evaluation of the transsphenoidal and pterional approaches. Neurosurgery 36:715-724, 1995

14. Qi S, Lu Y, Pan J, Zhang X, Long H, Fan J: Anatomic relations of the arachnoidea around the pituitary stalk: relevance for surgical removal of craniopharyngiomas. Acta Neurochir (Wien) 153:785-796, 2011

15. Rawal RB, Kimple AJ, Dugar DR, Zanation AM: Minimizing morbidity in endoscopic pituitary surgery: outcomes of the novel nasoseptal rescue flap technique. Otolaryngol Head Neck Surg 147:434-437, 2012

16. Shah RN, Surowitz JB, Patel MR, Huang BY, Snyderman $\mathrm{CH}$, Carrau RL, et al: Endoscopic pedicled nasoseptal flap reconstruction for pediatric skull base defects. Laryngoscope 119:1067-1075, 2009

17. Wang KC, Hong SH, Kim SK, Cho BK: Origin of craniopharyngiomas: implication on the growth pattern. Childs Nerv Syst 21:628-634, 2005

18. Wang KC, Kim SK, Choe G, Chi JG, Cho BK: Growth patterns of craniopharyngioma in children: role of the diaphragm sellae and its surgical implication. Surg Neurol $\mathbf{5 7}: 25-33,2002$

19. Yaşargil MG, Curcic M, Kis M, Siegenthaler G, Teddy PJ, Roth P: Total removal of craniopharyngiomas. Approaches and long-term results in 144 patients. J Neurosurg 73:3-11, 1990

\section{Disclosures}

Dr. Prevedello has been a consultant for Stryker, Medtronic, and Codman; holds a patent with KLS-Martin; has received honorarium from Leica Microsystems; and has received clinical or research support from Storz for the study described. Dr. Carrau is a consultant for Medtronic.

\section{Author Contributions}

Conception and design: Prevedello, Jamshidi, Beer-Furlan, Elzoghby, Safain, Carrau, Jane, Laws. Acquisition of data: all authors. Analysis and interpretation of data: all authors. Drafting the article: all authors. Critically revising the article: all authors. Reviewed submitted version of manuscript: all authors. Statistical analysis: Jamshidi, Beer-Furlan, Sahyouni. Study supervision: Laws.

\section{Correspondence}

Daniel Prevedello: Ohio State University, Wexner Medical Center, Columbus, OH. daniel.prevedello@osumc.edu. 